\title{
Multi-Stakeholder Focus Groups on Potential for Meat Inspection Data to Inform Management of Pig Health and Welfare on Farm
}

\author{
Nienke van Staaveren ${ }^{1}(\mathbb{D})$, Bernadette Doyle ${ }^{2}$, Alison Hanlon ${ }^{3}$ (D) and Laura A. Boyle ${ }^{2,4, *(\mathbb{D})}$ \\ 1 Department of Animal Biosciences, Ontario Agricultural College, University of Guelph, Guelph, \\ ON N1G 2W1, Canada; nvanstaa@uoguelph.ca \\ 2 Pig Development Department, Teagasc Animal and Grassland Research and Innovation Centre, Moorepark, \\ Fermoy, P61 C996 Co. Cork, Ireland; bdoylemvb@protonmail.com \\ 3 School of Veterinary Medicine, University College Dublin, Belfield, D04 W6F6 Dublin, Ireland; \\ alison.hanlon@ucd.ie \\ 4 Department of Animal Behaviour, Institute of Genetics and Animal Breeding of the Polish Academy of \\ Sciences, ul. Postepu 36A, Jastrzebiec, 05-552 Magdalenka, Poland \\ * Correspondence: laura.boyle@teagasc.ie; Tel.: +353-(0)254-2389
}

Received: 20 January 2019; Accepted: 13 February 2019; Published: 19 February 2019

check for updates

\begin{abstract}
Meat inspection (MI) findings can act as a valuable source of information on pig health and welfare. The PIG WELFare INDicators (PIGWELFIND) project (Research Stimulus Fund 11/S/107) was developed to progress the development of ante and post mortem MI as a pig health and welfare diagnostic tool in Ireland. Three multi-stakeholder focus groups were organized to explore areas of conflict and agreement between stakeholders' vision for including pig health and welfare indicators in MI and on how to achieve this vision. Each focus group consisted of eight stakeholders: pig producers, Teagasc pig advisors, pig processors, veterinarians involved in MI, private veterinary practitioners, and personnel with backgrounds in general animal health and welfare and food safety policy. In general, stakeholders expressed positive attitudes towards the use of MI data to inform pig health and welfare when standardization of recording and feedback is improved, and the MI system provides real-time benchmarking possibilities. Most emphasis was placed on health indicators as a first priority, while it was felt that welfare-related indicators could be included after practical barriers had been addressed (i.e., line speed/feasibility, standardization and training of meat inspectors, data ownership). Recommendations are made to further progress the development of MI as a pig health and welfare diagnostic tool and address some of these barriers.
\end{abstract}

Keywords: perspectives; meat inspection; swine; veterinarians; pig producers; processors; social science; welfare; health; management

\section{Introduction}

In recent years, interest in the potential of existing data sources to inform animal health and welfare is increasing [1,2]. Meat inspection (MI) databases are such a source and they play an important role in pig health surveillance and in the development of disease prevention strategies in numerous countries [3-6]. Apart from pig health, MI data can potentially provide valuable information on pig welfare and so contribute to the control of a range of pig health and welfare issues [6-10]. Stark et al. [10] suggested that MI could be efficient at identifying producers with animal health and/or welfare issues, similarly shown by van Staaveren et al. [7], and recommended that this information should be shared with veterinarians and producers. In fact, several pig health schemes such as the Wholesome Pigs Scotland (WPS) and British Pig Executive (BPEX) Pig Health Scheme (BPHS) in the UK [11], 
or the Animal and Public Health Information System (APHIS) in combination with the Pig Grading Information Scheme in Northern Ireland (PiGIS) [6], already provide producers and veterinarians with reports on pathological lesions recorded at MI and/or reasons for condemnations and which allow benchmarking to various degrees (e.g., against previous batches, against average figures, against bottom/top producers). Currently, in the Republic of Ireland no such system is in place and the PIG WELFare INDicators (PIGWELFIND) project (Research Stimulus Fund 11/S/107) was developed to progress the development of ante and post mortem MI as a pig health and welfare diagnostic tool.

Stakeholder involvement is vital to the success of such projects and two-way communication should occur between stakeholders to optimize possible benefits [12]. Previously, we presented results of semi-structured interviews with pig producers [13] and other stakeholders [14] from the Republic of Ireland and Northern Ireland aimed to identify their perspectives on MI and strengths, weaknesses, opportunities and threats of MI as a pig health and welfare diagnostic tool. The aim of this study was to elaborate on areas of conflict and agreement between stakeholders by bringing them together for a dynamic, in-depth exploration of the potential for MI as a pig health and welfare diagnostic tool. Three concurrent focus groups were held to share research findings of the PIGWELFIND project, discuss stakeholders' vision for including pig health and welfare in MI and ideas on how to achieve it.

\section{Materials and Methods}

Twenty-four stakeholders directly involved in MI or in the outcome of MI were invited to attend a one-day workshop at NovaUCD, University College Dublin (UCD), Ireland in November 2015. Participants were selected using a purposive sampling technique and recruited through their various representative organizations [14]. Three concurrent focus groups (FG1-3) were established consisting of pig producers (PP), Teagasc pig advisors (TPA), pig processors (PROC), veterinarians involved in meat inspection (VMI), private veterinary practitioners (PVP), and personnel with backgrounds in general animal health and welfare and food safety policy (GEN). Each focus group comprised 8 individuals following best practice for optimal size of focus groups and accounting for the diversity of the different stakeholder categories [15]. Each focus group was moderated by a trained facilitator assisted by a reporter for note taking and audio-recording. Two $1 \mathrm{~h}$ sessions were held: (1) "Visioning session"- to investigate stakeholders' vision for MI incorporating pig health and welfare measures; and (2) "Grounding session" - how to achieve this vision. In the visioning session, participants asked what they would start, stop or continue in the current MI process, to identify their needs and wants for an MI system that would incorporate measures of relevance to pig health and welfare, and to establish how such a system could be used to their benefit and the benefit of the industry as a whole. This discussion was used to form a common industry vision, which was discussed in a plenary session with all participants. Following this, the three focus groups reconvened to discuss the identified vision in the grounding session using a set of questions designed to determine the "what, how, where and who", necessary to achieve the common industry vision. Specifically, we explored the type and detail of pig health and welfare lesions that should be recorded, how this recording could be accomplished in a standardized manner and at which points during the MI process. Roles and responsibilities for the recording of data, training needs, and how data should be reported to other stakeholders were also discussed. Focus groups were audio-recorded and recordings were transcribed verbatim. Participants were coded using their stakeholder category followed by their focus group number e.g., PP-FG1 indicates a pig producer in the first focus group. The transcription data were organized by stakeholder group for both the visioning and grounding session. Comments relating to pig health and welfare were extracted to identify key issues and determine whether these were similar or different amongst the focus groups. Key issues were identified when they were mentioned by multiple participants or in more than one focus group. Examples are presented in the results. This study complied with UCD Research Ethics Guidelines and qualified for exemption from full ethical approval by the University of Dublin Human Research Ethics Committee (UCD HREC) (LS-E-15-137-Hanlon). 


\section{Results}

All invited participants consented to take part in the focus groups, however, 1 PVP had to cancel at short notice and was not present on the day of the workshop (FG3). The following key issues were identified during the workshop: technical and training requirements for an MI recording system, the inclusion of pig health and welfare in an MI recording system, and the use of MI data to inform management of pig health and welfare on farm.

\subsection{Technical and Training Requirements for a MI Recording System}

Improvements to the current MI process in recent years were acknowledged (e.g., PP-FG3: "we have a certification system at the moment, it is better than what was there a few years ago, we are getting a bit of information now all right ... "). However, all participants agreed on the need for data capture and the importance of a computerized system, rather than the current paper-based one, to facilitate user-friendly data capture. As stated by one veterinarian involved in MI (VMI-FG3):

VMI-FG3: "I want to put down a part condemned or a carcass condemned or I want to mark the tails from this particular batch of pigs ... I want to write it down and here I am with a dirty, wet, bloody hand, so computerization in whatever form is a necessity."

Computerized systems in combination with a more visual approach to MI was considered critical to allow meat inspectors the time to record data (VMI-FG1). Factory facilities, line speeds and staffing issues were also brought up as important factors in time and convenience constraints on meat inspectors' ability to record data.

VMI-FG1: "I think we have a very good basic system in place. We have two or three highly qualified people around every factory looking at carcasses, observing pigs coming in. What is not happening is that we are not capturing the data that they can generate. That is what we need to do."

Line speeds and workload were important barriers for veterinary meat inspectors and different solutions were offered to address these issues. Participants suggested increasing the number of people on the line, bringing in agricultural officers or training other general operators on the line to do some of the recording (GEN-FG2, VMI-FG3). However, one processor was hesitant to transfer tasks to general operators on the line (PROC-FG2) and also others recognized the importance of a simple scoring system in this case due to their varying backgrounds (TPA-FG2).

VMI-FG3: "If you are talking about something like faecal contamination, bile contamination and maybe even wounds and tails [tail lesions] you don't have to be a veterinary surgeon to do those things, but where pathology comes in, where ante-mortem comes in, where identification of diseases on a load of pigs arriving in a plant comes in, that is a different story."

PROC-FG2: "I don't know ... If it was, an agricultural officer, he could take the time to get the same information, they are there as well. I couldn't be putting it back onto [the general operator], I mean there is language barriers with operatives on the line. There are people being rotated, they haven't been trained up on this like you know. It is accuracy of the information as well you know."

TPA-FG2: "The scoring system is a simple scoring system. So when you have got some people that speak different languages, different levels of training, education, you will have to have it mild moderate, severe [lesion categories]."

While no clear solutions were agreed upon, it was stated that any form of a recording system would represent on improvement on the current system (GEN-FG3). Another suggestion was to focus on specific conditions individually in an effort to reduce the workload of inspectors (VMI-FG2).

GEN-FG3: "We have no recording system at the moment basically. It is a plus for everybody that [implementing a recording system] would happen." 
VMI-FG2: "For example, if you just decide to do on a particular batch a lesion specific data collection you are only collecting data purely on enzootic pneumonia (EP) or ascariasis, you could easily do that and incorporate that into the temporary veterinary inspector (TVI) work, you are just pressing a button in this instance and possibly just noting severity on the scale. Certainly incorporate one single pathology at a time. Very easy, possibly."

Having qualified veterinarians to do the ante and post mortem MI was considered an asset. However, variation between inspectors and a lack of guidelines as to what constitutes a "welfare problem" was an issue (VMI-FG1). This continued the discussion of standardized training and retraining of inspectors and the need for assessment to determine the effectiveness of this training (VMI-FG1, GEN-FG2).

VMI-FG1: "There is no red flag issue as to what is a red line for a welfare problem, when it definitely gets reported. Like 'oh God look at that, oh that is terrible', there is no structure. So it is a la carte for whoever is there on the day and I mean there is variation between condemnations, there is certainly variation between tolerances of welfare..."

VMI-FG1: "Training is fine, but you have to verify whether that training is effective, so I think there is a role for the veterinary inspector there ... seeing if all the veterinary inspectors in their individual factories are doing it to the required standard... Training and assessment. You can give all the training in the world, but if somebody doesn't implement that or take it in for whatever reason then there is a problem."

\subsection{The Inclusion of Pig Health and Welfare in a MI Recording System}

There was an emphasis on health rather than welfare measures to be included in the MI process (VMI-FG1), from viscera and carcass inspection, even if they did not lead to condemnations.

VMI-FG1: [regarding recording of health or welfare measures] "You have to get one thing right. You have to take baby steps. Ideally we would like the whole thing to be streamlined, but that [health] is the most important thing and if we can get that right we can build on that."

Most participants were in agreement that health indicators that resemble "invisible diseases" such as pneumonia, pleurisy and milk spot should be included. Processors tended to have a different motivation for recording pleurisy than producers. Their concerns were associated with the logistical issue of processing carcasses affected by pleurisy as it slows down the slaughterline (PROC-FG1). Additionally, processors were more interested than producers in the inclusion of indicators related to carcass quality and traceability such as bruising, fight marks, or unidentifiable/incorrect slap marks.

PROC-FG1: "From a processors point of view, anything that costs us time or money, we want addressed. So from our point of view, the pleurisy is a massive issue."

Despite heavy focus on health-related indicators, welfare-related issues such as casualty animals observed at ante mortem MI were prominently discussed, in addition to the impact it can have on public perception (VMI-FG1), as well as retailer demands related to pig welfare issues (PROC-FG2).

VMI-FG1: "Some of those things [red flag welfare issues e.g., downer pigs, pigs with large hernias, pigs that cannot walk off the lorry] basically shouldn't leave the farm. ... you can deem that animal a casualty and that means that that animal will have to have an antibiotic sample taken, if put in the chill it has to sit there for four or five days perhaps until a result comes back, that sends a message. No processor wants that and the message in a subtle way can go back to the primary producer, 'look don't be sending me in that rubbish'."

PROC-FG2: "From a retailer point of view we are already recording tail lesions as a customer requirement. We have to do three loads of 50 per day and we have to submit it every three months 
roughly and that gives us outcomes for the factory. So retailers are looking at that and there are also going on the pig farms and they are measuring bursitis and they will do a couple of pens of pigs and they will put their hand into the pen and they will crouch down and see their interaction between humans and things like that. So welfare is a big thing for retailers as well."

\subsection{Level of Detail in MI Data Recording}

In line with determining which indicators to include in the MI process, discussion quickly moved to the practical issue of the value of recording detailed information on a range of indicators including their severity versus the ability of meat inspectors to accurately record this in light of the limited time availability. This discussion came up across all three focus groups repeatedly as illustrated below.

TPA-FG2: "If you are going to score something you are going to limit the number of things you can record." "So if you include more measures with less detail is that more valuable?"

GEN-FG2: "I would value add this information, ... describing the severity of lesions and extent and that is a value add because it is more meaningful to the producer."

VMI-FG2: "Realistically if we were to complete the full guidelines of the hygiene package, all the examinations that we have to do realistically there is no time for data input... perhaps you are looking for a separate person not necessarily a vet to do the data input."

GEN-FG2: "The solution for that is you are physically capable of doing X [pigs] per hour. If you want to do more than X per hour you either actually put on more people or you modify the line [splitting the line and putting people on the sublines]."

PVP-FG1: “With pleurisy you just need yes/no. With pneumonia if you just got lesions/no lesions, or if you broke it down into maybe pigs with more than $10 \%$ of the lung affected, something like that. At least then it raises a flag and the guy can get his own vet to go in and have a proper look and take samples then."

VMI-FG1: "Yes. But if you don't grade that then how do you differentiate?"

PVP-FG1: "It is not very sophisticated, but I think that is all we can do."

VMI-FG1: "It gets the system up and running. As technology evolves and as people get more used to it, then it can be stretched out a bit or we can go into it a little deeper. But just to get a platform up there would be a huge step and would deliver a lot and let's just grasp that much."

VMI-FG1: "On the viscera you have roughly 26 individual things to do in eight and a half seconds as is and then sterilise yourself in between to avoid cross contamination. And then stick a panel in there for recording post-mortem data. So yeah, it shouldn't be any trouble ... [sarcastically]"

PROC-FG3: [regarding binary scoring] "But would you learn anything from that though? Like that doesn't teach you anything."

GEN-FG3: "You could get it [pleurisy] to that level [different severity scores] but it is just when you introduce so many different grades then it is consistency of findings. We did the same with pneumonia, are pneumonias limited or extensive." ... "any post-mortem system that we will be developing for pigs would have tail lesions, ..., we would record any pathology, ..., that is a basic requirement of any post-mortem data capture system. But the scoring would be in addition kind of, you know."

Discussions on how to possibly address this issue suggested ensuring a user-friendly data capturing system, with clear and agreed-upon definitions and photographs to assist with identification, limit the number of indicators to be recorded to a maximum of four or five conditions, communication between inspectors and to assess a subset of pigs per batch. For example, PVP-FG2 preferred to inspect batches when farmers were sending the worst performing pigs as they would be most seriously affected rather than the best performing pigs that would not have any issues. 


\subsection{The Use of MI Data to Inform Management of Pig Health and Welfare on Farm}

\subsubsection{Method of Feedback and Behavioural Change}

In general, all three focus groups and all stakeholder categories agreed on the importance of standardized feedback for producers and other stakeholders (GEN-FG2, PVP-FG1). Quick and visual feedback was highlighted so that it would allow for benchmarking and for producers to devise a plan to manage their herd health (TPA-FG3).

GEN-FG2: "Thing I would start is collecting relevant data in a manner that allows analysis and feedback to the various stakeholders, I would start that in the morning if I could."

PVP-FG1: "What we need to add some value to it [meat inspection] is an on-going reporting of health indicator lesions, to point spot the pneumonia, the pleurisy ... they are getting on-going feedback and a producer can then go back to his own advisor, nutritionist, vet or whatever... I have an indicator here that you have a problem and can each of you look at it, there is something going on."

TPA-FG3: "For every pig producer, he can go online an hour after the pigs [went through the meat inspection process], and you can do it by load, it will do it over a time frame and it will measure a huge amount, like pleurisy levels, milk spot, lesion scoring on the lungs, ... that gets back to him [producer] immediately and he can look at it on a per load basis, he can look at it on a monthly basis, weekly basis, seasonal basis and most important is it benchmarks against the factory."

However, a processor expressed some doubt that the information would be used proactively by producers (PROC-FG1) and another processor echoed a need for information on the effectiveness of implementing such a system in terms of higher quality (health/welfare) pigs arriving at the factory. This concern was refuted by a producer claiming that this impression was likely due to the currently fragmented nature of the feedback received by producers (PP-FG1).

PROC-FG1: "I would like that whatever information goes back to the farmers that the farmer would take action on the information he is getting ... I have a suspicion that a lot of farmers that are bringing pigs into the factory and the pigs are displaying pleurisy or tail biting or liver spot, they are actually aware of it already..."

PP-FG1: "I believe most producers nowadays ... especially as their margins are very tight are going to look at that data and say this is a problem on my farm, implement a vaccine, get it sorted from the vet's point of view. It is going to save me money in the long term. I do believe the trouble is, it's coming back in bits and pieces... whereas if you had a reporting system there, that is on a weekly basis, I do believe the farmers would utilize it."

In a separate focus group, where participants discussed the beef MI system where welfare and health checks were implemented, similar views were expressed (GEN-FG3). Others also highlighted the importance of showing economic impacts, which would be possible with improved feedback to producers, as a driver for changing producer behaviour (GEN-F2).

GEN-FG3: [re: beef MI system] "I would say one thing that has improved and this is probably through all plants, the number of casualty animals we get in has kind of vanished." .. "The advantage of this is that all information from these issues of welfare will be visible and they will just reduce."

GEN-FG2: "One way is to build tools for analysis of all pathologies ... . all about building the economics behind the liver and lung lesions that we find. It is a big driver for farmer behaviour... reporting back to the farmers not just the pathologies but also the economic impact of the pathology."

One pig producer pointed out the importance of educating all pig farm staff on the information that would be provided through MI in order to elicit behavioural change (PP-FG3). 
PP-FG3: "But equally the farmer and the guys on the pig farms have to be educated, it's their financial loss at the end of the day,... you are depending on them for the health status of your unit and you are trying to keep security, ... it is important for your vet that he can give all that information down to the guys on the unit.

Apart from some concerns, generally most stakeholders anticipated that the implementation of a MI system that includes measurements on pig health and welfare, combined with regular feedback to producers, would improve the reputation of the pig industry. It would produce healthier, higher quality pigs and it could contribute to disease surveillance on a national level. Additionally, it would lead to financial benefits by reduced losses and being able to perform cost-benefit analysis of management interventions (PP-FG1). Additionally, veterinary meat inspectors mentioned an improved level of job satisfaction (VMI-FG1).

PP-FG1: "from a producer point of view, the more that is reported back then, from the point of view of getting problems solved, there is a serious financial benefit that producers probably aren't getting [currently], it [high prevalence of disease] is only highlighted to them when it is a massive problem and that is nearly too late."

VMI-FG1: "It would be better for your role, it would be more satisfying with what you are doing. It is actually producing a benefit to the producer through the feedback. I think it would be better for everybody."

\subsubsection{Concern about Use of Data to Penalize the Producer}

There was some discussion on how the information collected during MI would be used. Worries about data being used against producers with a "stick-approach" leading to "department" (i.e., regulatory authority) inspections were brought up (TPA-FG2) and indeed, processors were not opposed to paying less for a lower quality product or implementing financial penalties as a way to change producer behaviour (PROC-FG1, GEN-FG3). It was countered by others that this should not occur unless there were sustainable ways to deal with the issue (i.e., tail biting, PP-FG2) and that the MI system should give producers time to make management changes, and possibly even the option of providing financial incentives to make housing or husbandry changes. However, the producer also acknowledged that support and good inter-stakeholder relationships were needed to support the MI system and to see the overall benefits and positive potential of such data for the industry (PP-FG2).

TPA-FG2: "I suppose all that people are worried about is, that if they have a high level of certain diseases that that will go back to the department and result in a department inspection."

PROC-FG1: "I know what I would do with it [meat inspection data] as a pig buyer. A pig buyer is the same as a buyer of shoes ... Quality equals money. If you are asked to buy a lower quality product you pay less for it."

PROC-FG1: "The only way to change that culture [sending casualty pigs] and I have said it is to charge $€ 100$ per pig that arrives in that way. If a pig arrives in and he is off his legs, $€ 100$ and $€ 100$ for the hauler as well, double charge them. It will prevent the hauler taking instruction from the farmer to take the pig on the lorry, it will prevent the farmer from sending the pig in in the first place."

GEN-FG3: "When we report a lot of stuff and nothing is being done about it. There is a number of possibilities that can happen. But unless there is a penalty on the farmer it is not going to improve."

PP-FG2: [re: financial penalties for pigs with tail lesions or not accepting tail docked pigs] "We are getting absolutely nothing more for our pigs, so when we start to realise YOU HAVE TO PAY THE PRODUCER FOR THESE THINGS." ... " So when you come up with a financial package for us to do the job on a sustainable basis, long term basis, I will agree to that." 
PP-FG2: "Of course you have fears that fellas are going to use the stick approach. That is up to us to instill confidence in the suppliers .... if the vets are coming on side with the farmers and saying we want to do this. This is a good job and the factories are reassuring us that it is not going to be used and the farmer agrees to it."

\section{Discussion}

This study presents findings of three multi-stakeholder focus groups held to elaborate on views on the potential for electronic data capture at MI as a pig health and welfare diagnostic tool in the Republic of Ireland. To the authors' knowledge this was the first time that different stakeholders (i.e., pig producers, pig processors, pig advisors, veterinarians involved in meat inspection, private veterinary practitioners, and personnel with backgrounds in general animal health and welfare and food safety policy) were brought together for in-depth dynamic discussion on this topic. Allowing multiple stakeholders to discuss issues of conflict and agreement in one group was considered advantageous in progressing and elaborating on the different views that were expressed during "one on one" interviews with individual stakeholders [13,14]. The novelty of this project was to incorporate health and welfare indicators in the MI process. The advantages of assessing pig health and welfare at MI have previously been described, ranging from a large amount of data collection, higher visibility of certain conditions, reduced risk to biosecurity and disease transmission compared to on-farm assessments $[6,16,17]$.

\subsection{Technical Requirements for a MI Recording System}

\subsubsection{Abattoir Facilities-Computerization and User-Friendliness}

All participants agreed that in order for an MI recording system to be successful it would need to be computerized rather than the manual, paper-based recording of condemnations that is currently used in Irish pig abattoirs. Many of the participants recognized the importance of proper infrastructure and qualified personnel in abattoirs to allow MI recording including prerequisites for data collection such as slaughterline construction and line speeds that allow data recording. User-friendly facilities were considered especially important because many of the veterinary inspectors involved in MI were elderly. These logistic requirements described by participants are in line with those set out by Korkeala and Lundén [12], who identified the need for high quality data collection in abattoirs.

\subsubsection{Continued Training of Personnel and Standardization of MI Data Collected}

The use of qualified veterinarians performing MI was valued by the majority of participants and considered an asset for the Irish pig industry on the global market. Line speed and current responsibilities of veterinary meat inspectors constrain the scope of recording additional indicators at MI. However, it was recognized that other operatives could be trained to record non-pathological indicators (e.g., tail lesions). In fact, Harley et al. [6] showed the roles and responsibilities and training for MI professionals in other EU member states, which included non-veterinarians. Furthermore, the implementation of a visual-only MI system would give meat inspectors more time, however, this practice is challenged by international trade standards [18].

Regardless of who performs MI, training and standardization are major issues which could affect the potential of MI as a pig health and welfare diagnostic tool [6]. Interestingly, while participants praised veterinary meat inspectors as being highly qualified, they also acknowledged the lack of continued training and assessment provided. Continued training is important to support standardization of what constitutes a health or welfare issue $[19,20]$. The lack of proper definitions of MI measures is a contributory factor. These issues need to be addressed to develop accurate health and/or welfare indicators that can be used at MI [21-23].

Differences between abattoirs or inspectors leads to distrust among producers regarding the quality of MI data, which could undermine the usefulness of MI to inform pig health and welfare $[13,24]$. 
Differences exist between findings made by meat inspectors or pathologists/veterinary researchers, with the latter typically showing higher sensitivity [21,25-27], which is probably due to different roles and responsibilities and the associated time constraints.

\subsection{The Inclusion of Pig Health and Welfare in a MI Recording System}

\subsubsection{Health and Welfare Indicators}

Currently, the MI process in Ireland focusses on condemnations which are one of the more serious outcomes of MI with the largest financial consequences for producers and abattoirs [6]. Condemnation rates and reasons for condemnations could provide valuable information on the health and welfare of pigs. Pigs condemned for health issues are likely to have had reduced welfare [28], and other causes of carcass condemnation such as abscesses could indicate welfare issues [29]. Apart from carcass condemnations, condemnations of viscera for health reasons could also be informative [13]. Furthermore, participants also recognized the value of recording indicators of impaired pig health/welfare even if these do not necessarily lead to condemnations.

Two out of the three the focus groups recognized that health is a part of welfare, while it was not explicitly discussed in the third focus group. Health is a part of the three common viewpoints (i.e., physiological functioning, feelings and affective states, and natural living) of animal welfare [28]. Most participants focused on health rather than welfare measurements, although those with expertise in animal health and welfare and food safety policy placed greater emphasis on welfare indicators. This is in part likely due to the view held by most producers and veterinarians that animal welfare is mainly comprised of health and performance $[28,30]$. Financial considerations are an important driver for herd health management, to reduce the impact of disease on performance and mortality [31]. In addition, the perceived ability of producers to control these issues more successfully than welfare issues such as aggression [32] or tail biting [33] can play a role. Bruising and skin lesions are important indicators of pig welfare on-farm $[7,34]$. They often reflect problems with aggression which impede productivity and economic returns [35]. In spite of being aware of such implications [32], pig producers did not discuss the potential for inclusion of such lesions in the MI process. This is likely because they do not consider aggression as an issue on their farm [32]. The same considerations can be made for tail lesions $[29,30,33,36]$. In contrast, processors were keen to record bruising and skin lesions because of their implications for carcass quality and not their relevance to animal welfare.

Additionally, participants did not prioritize welfare indicators (e.g., bursitis, tail lesions, abscesses) as they believed they would be visible on-farm, despite the fact that previous research showed increased visibility when recording these welfare lesions at MI [16]. Moreover, MI was considered to offer the opportunity to record "invisible" health indicators at MI, i.e., those that could not be observed on-farm, contributing to the emphasis on health indicators. The value of receiving information on viscera lesions or "invisible diseases" such as pneumonia, pleurisy and milk spot for producers was previously reported by Devitt et al. [13].

The inclusion of more welfare-related indicators was conditional on addressing logistical barriers. Whilst MI originally evolved to protect public health, it is now also recognized as an important benchmark of animal health and welfare [37]. Furthermore, pig welfare indicators such as tail and skin lesions reflect on-farm herd health and welfare [7,38], as well as reduced productivity $[29,34,36]$, therefore the inclusion of welfare indicators at MI has an important utility in providing valuable data to inform herd management and health planning. In fact, improved animal welfare can lead to financial benefits for producers and society through reduced mortality, improved health, improved product quality, improved disease resistance and reduced medication, lower risk of zoonoses and foodborne diseases, farmer job satisfaction, contribution to Corporate Social Responsibility, and ability to command higher prices from consumers [39]. 


\section{Casualty Animals}

One major welfare and regulatory issue discussed in-depth, was casualty animals (i.e., animals not fit to travel which is in contravention of the Council Regulation (EC) No. 1 of 2005 on the protection of animals during transport). Participants were unanimous that casualty animals should be euthanised on-farm. There are numerous barriers to on-farm euthanasia including stock person attitudes, beliefs about the work environment, inappropriate equipment and methods, and factors related to decision-making [40]. However, failure to euthanise casualty pigs leads to suffering and increased costs for feed, housing, and medication [41]. Effective on-farm euthanasia methods are clearly needed for the pig industry and will reduce animal suffering as well as the reputational risk of images of casualty animals reaching the public [42], which was a concern frequently expressed by stakeholders. Best practice guidelines for on-farm euthanasia of pigs in Ireland were published recently [43].

\subsubsection{Location of MI and Representativeness of Pigs Observed during the Slaughter Process}

Both ante and post mortem MI were considered important for monitoring animal health and welfare. Conditions such as dead-on-arrival, lameness and hernias are more easily recorded during ante mortem MI and can reflect conditions on farm and during transport. Whilst "invisible diseases" could be recorded at post mortem MI. However, one limitation of MI is that it may not reflect all on-farm risks to pig health and welfare, for example, when pigs are euthanised on farm or are diverted as casualty animals at ante mortem MI or have died during transport or lairage [11,44-46]. Interestingly, one PVP preferred to inspect batches of pigs originated from hospital pens or the last pigs of a batch to be sent for slaughter as these would typically be the weaker pigs with the most health and welfare issues.

\subsubsection{Level of Detail in MI Data Recording}

Perceived barriers in terms of line speed and standardization of recording, led most participants to suggest recording lesions on a binary scale even though the added value of recording the extent and severity of lesions was acknowledged. Current pig health schemes such as the Wholesome Pigs Scotland (WPS) and the BPEX Pig Health Scheme (BPHS) record the majority of lesions on a binary scale, though EP-like lesions and pleurisy are scored according to severity or extent of the lesions [11]. While binary scoring would be more practical in current MI conditions, it may result in the recording of more severe conditions and underestimate the actual prevalence of the indicators [21]. For example, binary scoring of tail lesions would lead to recording of severe tail lesions which represents a small proportion of tail lesions observed at MI, while most variation occurs in the less severe tail lesions which indicate tail-directed behaviour on-farm and can be used as iceberg indicators for pig welfare $[7,36]$. Recording tail length would offer an alternative, binary assessment capable of indicating whole life welfare of pigs [34,47]. Incorporation of the extent or severity of lesions was considered an option in the future when there is a good working system in place with personnel familiar with the MI terminology, standardization and processes. Previous studies showed variation for post mortem measurements with different levels of gradation by official meat inspectors [22,48]. A larger variation between meat inspectors was reported for pathologies with different levels of gradation such as pneumonia, milk spots, pleuritis and scabies/skin lesions [22]. A binary scale simplifies recording and requires less training compared to a gradated scoring scale [23]. Solutions to other logistical barriers such as line speed and work load of inspectors to allow for a greater level of detail in data recording included training agricultural officers to record some data, and rotating the assessment of different types of lesions per batch. 


\subsection{The Use of MI Data to Inform Management of Pig Health and Welfare on Farm}

\subsubsection{Method of Feedback}

In order to gain the most out of the MI process, data should be communicated to stakeholders. Improved communication of MI data is important for transparency and to increase the trust of consumers and other stakeholders. Two-way communication should occur between stakeholders to optimize possible benefits [12]. Consistent feedback on a weekly basis would provide an evidence-based approach to herd management, to reduce the financial costs associated with carcass condemnation. Real-time feedback was considered advantageous by all stakeholder groups, because it would also allow farmers to benchmark their performance over time, against abattoir and/or national average.

As mentioned, the feedback from abattoirs is currently often limited to carcass condemnations, provided on hand-written certificates [6]. Semi-structured interviews which were previously conducted with pig producers from the Republic of Ireland and Northern Ireland also acknowledged the limitations of the current MI reporting system [13]. Visual reporting in an integrated, central database with financial analysis showing economic impacts, and benchmarking options were highly valued.

\subsubsection{Facilitation of Behavioural Change}

Raising awareness of pig health or welfare issues might elicit behavioural change by producers as highlighted by a participant's experience with implementation of health and welfare checks at MI in the beef sector, which resulted in a reduction in casualty cattle being transported for slaughter. Other work also indicates positive effects of raising awareness and assessment programs in terms of animal health and/or welfare, for example, reducing tail biting in pigs [49], lameness and hock injuries in dairy herds [50], and injurious pecking in laying hens [51]. Continuous monitoring and feedback of MI data could increase awareness on different health and welfare issues in pig producers and allow them to evaluate their herd health and welfare management plans [13,47]. Inclusion of welfare indicators at MI can provide valuable information on the prevalence of certain welfare issues and this increased awareness could ultimately lead to behavioural changes and on-farm improvements in pig welfare.

Financial impact or incentives are considered important drivers to facilitate behavioural change and farmers state they will change practices if it will lead to financial returns [52]. Several studies evaluated the economic impact of different farm practices, for example, showing that the use of biosecurity practices can reduce antimicrobial use in a cost-effective way [53]. However, financial incentives are not always required to elicit behavioural changes. For example, Chapinal et al. [50] reported that benchmarking against other farms was enough to motivate behavioural change and reduce the prevalence of lameness and hock injuries. This highlights the importance and value of benchmarking opportunities in the MI system. Similarly, while risk scores for tail biting were most strongly reduced in farms that received financial incentives, lower risk scores were also observed in control farms that were benchmarked but which did not receive financial incentives to change [49]. The researchers reported individual variation in the uptake of advice even when financial incentives were provided due to producers' attitudes [49], showing that financial incentives are not always sufficient to induce change. Indeed, producer attitudes to and their perceived ability to control certain health or welfare issues appear to play an important role, especially in regard to tail lesions $[30,33]$ and aggression [32] in pigs. This could explain the concerns expressed by producers in the current study regarding tail lesions stating that they require assistance in managing tail biting in a sustainable way due to small profit margins, and their opposition to penalties on carcasses with docked tails or tail lesions. Similar concerns were expressed by pig producers in the Netherlands when discussing rearing pigs with undocked tails or implementing different management strategies to reduce tail biting, as they felt they would be taking financial risks which would not necessarily pay off [30]. This is in line with the idea that producers are risk-aversive and act in a way which is in their economic best interest as there is currently no economic incentive for producers to stop tail docking [54]. 
Ideally, feedback to pig producers would include information on economic impact of health and welfare conditions, as well as advice on appropriate management strategies to reduce them, to allow producers to make judgments on cost-effectiveness. The proposed MI tool could therefore be modified to incorporate advice and function as a decision making tool (e.g., see German tail biting risk tool SchwIP $[38,55])$. The Teagasc eProfit Monitor, which collects technical and financial performance data for Irish pig herds, allows comparison in time and with the top 25\% producers [56]. A large number of Irish pig producers use this eProfit Monitor and so will already be familiar with benchmarking tools which could help their understanding of MI feedback. Connecting these two data sources, the MI system and the Teagasc eProfit Monitor, would be especially interesting in terms of analysis of financial implications as a method to encourage change in producer behaviour.

Knowledge transfer of MI findings including management strategies and their economic impact is important as a training tool for farmers and other relevant stakeholders such as veterinary practitioners or farm advisors. At the same time, care must be taken that producers are not overwhelmed with complex data [24] and one producer emphasized that farm personnel should be educated on the type of information the new MI process would provide them. We recommend that education on the MI tool would extend to all stakeholders including advisors, veterinarians, nutritionists, processors and meat inspectors [55]. Veterinarians are particularly important in this regard as they are often used, and they are trusted information sources for pig producers. Discussion and sharing of information among pig producers is also considered important [31,32] which was reiterated during the focus groups. Furthermore, when veterinary practitioners and farm advisors are informed, they can assist in the development of herd management plans to reduce the prevalence of health and welfare conditions $[13,14]$. Qualitative research such as a participatory co-design approach could help producers and other stakeholders to experience each other's viewpoint and may lead to shared understanding of the importance of welfare indicators and practice-ready tools [30].

\subsubsection{Concern about Use of Data to Penalize the Producer}

Some participants expressed concerns on the possibility of MI data being used against producers in the form of regulatory inspections and financial penalization for health or welfare problems which was reiterated by producers [13]. However, producers in the focus groups also pointed out that a good relationship between all stakeholders and a positive approach could help reduce these concerns and allow skeptical producers to understand the overall benefits information that a more comprehensive MI system could provide.

\subsection{Future Directions}

In order to provide producers with feedback, carcass and viscera identification throughout the slaughtering process is required $[6,17]$. Improved traceability is a prerequisite. Currently, the carcass can be linked to the farm of origin, however, when viscera are removed and the carcass is cut into separate parts, traceability is more difficult. Marking or tagging of the viscera are required to enable full carcass feedback to producers. The use of electronic tags, which would allow identification of individual pigs, and the rapid development in image analysis or machine learning, show promise in improving traceability and could allow automated data recording for pig health and welfare at high line speeds [57,58]. Automated detection of different lesions at MI is a promising new approach in research which is being currently being investigated for a variety of indicators such as lung, heart, liver, skin, ear and tail lesions as well as bursitis [38,59-61]. Ideally, this would allow integration and detailed recording of different indicators including but not limited to carcass condemnations, viscera condemnations, viscera lesions (e.g., lung lesions, gastric ulcers, milk spot), carcass lesions (e.g., tail lesions, skin lesions, loin bruising, ear lesions) or physiological measurements (e.g., blood lactate, creatine kinase, haptoglobin) in future MI systems to provide information on pig health and welfare $[6,13,47,58,62,63]$. Combining different indicators can increase the value of the obtained information [1], however, feasibility and costs would need to be addressed before implementation of 
an on-line pig health and welfare monitoring system. Additionally, longitudinal studies examining the implementation of the recording system, communication and use of feedback, and effects on farm performance in terms of health, welfare and productivity over time are needed to evaluate the long-term merit of recording health and welfare indicators at MI. Furthermore, studies examining the cost/benefit of pig health and welfare assessment using more or less detailed levels of recording (i.e., scoring scales or presence/absence of indicators) at MI from both and economic and societal point of view are warranted.

\section{Conclusions}

This paper presents findings of multi-stakeholder focus groups where different stakeholders were brought together to discuss their vision for including pig health and welfare in MI and how to achieve this vision in an effort to develop ante and post mortem MI as a pig health and welfare diagnostic tool in Ireland. In general, stakeholders expressed positive attitudes towards the use of MI data to inform pig health and welfare. We outline a framework for MI which incorporates health and welfare indicators and should address barriers described by stakeholders. MI findings should be recorded in a user-friendly, computerized system through a standardized recording protocol with clear definitions of included conditions. Meat inspectors should receive repeated training and assessment to guarantee standardized recording of MI findings. MI should continue at both ante and post mortem inspection points, with emphasis on casualty animals/animals unfit to travel at ante mortem inspection and "invisible" diseases or viscera lesions (e.g., pleurisy, pneumonia, milk spot), as well as welfare-related carcass lesions (e.g., tail lesions, skin lesions) at post mortem inspection. Training of meat inspectors should emphasize the multi-faceted purpose of the protection of public health as well as animal health and welfare. Conditions should be recorded on a binary scale (i.e., presence of absence) to accommodate line speeds and increase standardization and feasibility of the MI system. Further recommendations to increase feasibility and reduce workload are to record conditions only for a subset of pigs within a batch, rotational recording of different conditions to only focus on one condition per batch, and include agricultural officers or general operatives to record conditions which do not require identification of pathologies. Feedback of MI data should be provided in real-time and a visual manner to allow benchmarking over time, against abattoir or national averages. All stakeholders should be trained to interpret MI data and act on findings, with possible incorporation of risk assessment tools and cost-benefit analysis of management strategies to assist farmers' decision-making processes to reduce the prevalence of health and welfare conditions on farms.

Author Contributions: Conceptualization, B.D., A.H., and L.A.B; Methodology, B.D. and A.H.; formal analysis, N.v.S.; Investigation, N.v.S., B.D., A.H., and L.A.B.; Writing—original draft preparation, N.v.S.; Writing—review and editing, B.D., A.H., and L.A.B.; Project administration, B.D.; Funding acquisition, A.H. and L.A.B.

Funding: This study was part of the PIGWELFIND project funded by the Research Stimulus Fund (11/S/107) of the Irish Department of Agriculture, Food and Marine under the National Development Plan (2007-2013). We acknowledge the Walsh Fellowship Scheme for funding Nienke van Staaveren.

Acknowledgments: The authors would like to extend their gratitude to all participants of the stakeholder workshop.

Conflicts of Interest: The authors declare no conflict of interest. B.D. started employment at the Department of Agriculture, Food and Marine in 2018, two years after completion of the PIGWELFIND project. The funders had no role in the design of the study; in the collection, analyses, or interpretation of data; in the writing of the manuscript, or in the decision to publish the results.

\section{References}

1. Cornou, C.; Kristensen, A.R. Use of information from monitoring and decision support systems in pig production: Collection, applications and expected benefits. Livest. Sci. 2013, 157, 552-567. [CrossRef] 
2. Nielsen, A. Data warehouse for assessing animal health, welfare, risk management and -communication. Acta Vet. Scand. 2011, 53, S3. [CrossRef] [PubMed]

3. Elbers, A.R.W.; Tielen, M.J.M.; Snijders, J.M.A.; Cromwijk, W.A.J.; Hunneman, W.A. Epidemiological studies on lesions in finishing pigs in the Netherlands. I. Prevalence, seasonality and interrelationship. Prev. Vet. Med. 1992, 14, 217-231. [CrossRef]

4. Christensen, J.; Ellegaard, B.; Kirkegaard Petersen, B.; Willeberg, P.; Mousing, J. Pig health and production surveillance in Denmark: Sampling design, data recording, and measures of disease frequency. Prev. Vet. Med. 1994, 20, 47-61. [CrossRef]

5. Willeberg, P.; Gerbola, M.A.; Petersen, B.K.; Andersen, J.B. The Danish pig health scheme: Nation-wide computer-based abattoir surveillance and follow-up at the herd level. Prev. Vet. Med. 1984, 3, 79-91. [CrossRef]

6. Harley, S.; More, S.; Boyle, L.; Connell, N.O.; Hanlon, A. Good animal welfare makes economic sense: Potential of pig abattoir meat inspection as a welfare surveillance tool. Ir. Vet. J. 2012, 65, 11. [CrossRef] [PubMed]

7. Van Staaveren, N.; Doyle, B.; Manzanilla, E.G.; Calderón Díaz, J.A.; Hanlon, A.; Boyle, L.A. Validation of carcass lesions as indicators for on-farm health and welfare of pigs. J. Anim. Sci. 2017, 95. [CrossRef]

8. Knage-Rasmussen, K.M.; Rousing, T.; Sorensen, J.T.; Houe, H. Assessing animal welfare in sow herds using data on meat inspection, medication and mortality. Animal 2015, 9, 509-515. [CrossRef]

9. Pandolfi, F.; Edwards, S.A.; Maes, D.; Kyriazakis, I. Connecting Different Data Sources to Assess the Interconnections between Biosecurity, Health, Welfare, and Performance in Commercial Pig Farms in Great Britain. Front. Vet. Sci. 2018, 5, 41. [CrossRef]

10. Stärk, K.D.C.; Alonso, S.; Dadios, N.; Dupuy, C.; Ellerbroek, L.; Georgiev, M.; Hardstaff, J.; Huneau-Salaün, A.; Laugier, C.; Mateus, A.; et al. Strengths and weaknesses of meat inspection as a contribution to animal health and welfare surveillance. Food Control 2014, 39, 154-162. [CrossRef]

11. Sanchez-Vazquez, M.J.; Strachan, W.D.; Armstrong, D.; Nielen, M.; Gunn, G.J. The British pig health schemes: Integrated systems for large-scale pig abattoir lesion monitoring. Vet. Rec. 2011, 169, 413. [CrossRef]

12. Korkeala, H.; Lundén, J. Use of Meat Inspection Data. In Meat Inspection and Control in the Slaughterhouse; Ninios, T., Fredriksson-Ahomaa, M., Eds.; John Wiley \& Sons, Ltd.: Chichester, UK, 2014.

13. Devitt, C.; Boyle, L.; Teixeira, D.L.; O'Connell, N.E.; Hawe, M.; Hanlon, A. Pig producer perspectives on the use of meat inspection as an animal health and welfare diagnostic tool in the Republic of Ireland and Northern Ireland. Ir. Vet. J. 2016, 69, 2. [CrossRef]

14. Devitt, C.; Boyle, L.; Teixeira, D.L.; O'Connell, N.E.; Hawe, M.; Hanlon, A. Stakeholder perspectives on the use of pig meat inspection as a health and welfare diagnostic tool in the Republic of Ireland and Northern Ireland; a SWOT analysis. Ir. Vet. J. 2016, 69, 17. [CrossRef] [PubMed]

15. Rabiee, F. Focus-group interview and data analysis. Proc. Nutr. Soc. 2004, 63, 655-660. [CrossRef]

16. Carroll, G.A.; Boyle, L.A.; Teixeira, D.L.; Van Staaveren, N.; Hanlon, A.; O'Connell, N.E. Effects of scalding and dehairing of pig carcasses at abattoirs on the visibility of welfare-related lesions. Animal 2015, 10. [CrossRef]

17. Dalmau, A.; Fabrega, E.; Manteca, X.; Velarde, A. Health and Welfare Management of Pigs Based on Slaughter Line Records. J. Dairy Vet. Anim. Res. 2014, 1, 5-10. [CrossRef]

18. Alban, L.; Steenberg, B.; Stephenses, F.T.; Olsen, A.-M.; Petersen, J.V. Overview on current practices of meat inspection in the EU. Sci. Rep. Submitt. EFSA 2011, 152. [CrossRef]

19. Main, D.; Mullan, S.; Atkinson, C.; Bond, A.; Cooper, M.; Fraser, A.; Browne, W. Welfare outcomes assessment in laying hen farm assurance schemes. Anim. Welf. 2012, 21, 389-396. [CrossRef]

20. Palczynski, L.; Buller, H.; Lambton, S.; Weeks, C. Farmer attitudes to injurious pecking in laying hens and to potential control strategies. Anim. Welf. 2016, 25, 29-38. [CrossRef]

21. Bonde, M.; Toft, N.; Thomsen, P.T.; Sorensen, J.T. Evaluation of sensitivity and specificity of routine meat inspection of Danish slaughter pigs using Latent Class Analysis. Prev. Vet. Med. 2010, 94, 165-169. [CrossRef] [PubMed]

22. Schleicher, C.; Scheriau, S.; Kopacka, I.; Wanda, S.; Hofrichter, J.; Kofer, J. Analysis of the variation in meat inspection of pigs using variance partitioning. Prev. Vet. Med. 2013, 111, 278-285. [CrossRef] [PubMed] 
23. D'Eath, R.B. Repeated locomotion scoring of a sow herd to measure lameness: Consistency over time, the effect of sow characteristics and inter-observer reliability. Anim. Welf. 2012, 21, 219-231. [CrossRef]

24. Bondt, N.; van den Elzen, D.; Hoste, R.; van Wagenberg, C.; Vermeij, I.; van der Fels, B. Elimination of Slaughter Defects in the Pigmeat Chain; Report 5.04.04; Landbouw Economisch Instituut (LEI): Den Haag, The Netherlands, 2004.

25. Cleveland-Nielsen, A.; Christensen, G.; Ersboll, A.K. Prevalences of welfare-related lesions at post-mortem meat-inspection in Danish sows. Prev. Vet. Med. 2004, 64, 123-131. [CrossRef] [PubMed]

26. EFSA. Scientific report on the risks associated with tail biting in pigs and possible means to reduce the need for tail docking considering the different housing and husbandry systems (Question No EFSA-Q-2006-013). EFSA J. 2007, 611, 1-13.

27. Nielsen, S.S.; Nielsen, G.B.; Denwood, M.J.; Haugegaard, J.; Houe, H. Comparison of recording of pericarditis and lung disorders at routine meat inspection with findings at systematic health monitoring in Danish finisher pigs. Acta Vet. Scand. 2015, 57, 18. [CrossRef] [PubMed]

28. Fraser, D.; Weary, D.; Pajor, A.; Milligan, B. A Scientific Conception of Animal Welfare that Reflects Ethical Concerns. Anim. Welf. 1997, 6, 187-205.

29. Harley, S.; Boyle, L.A.; O'Connell, N.E.; More, S.J.; Teixeira, D.L.; Hanlon, A. Docking the value of pigmeat? Prevalence and financial implications of welfare lesions in Irish slaughter pigs. Anim. Welf. 2014, 23, 275-285. [CrossRef]

30. Benard, M.; Schuitmaker, T.J.; de Cock Buning, T. Scientists and Dutch Pig Farmers in Dialogue About Tail Biting: Unravelling the Mechanism of Multi-stakeholder Learning. J. Agric. Environ. Ethics 2014, 27, 431-452. [CrossRef]

31. Alarcon, P.; Wieland, B.; Mateus, A.L.P.; Dewberry, C. Pig farmers' perceptions, attitudes, influences and management of information in the decision-making process for disease control. Prev. Vet. Med. 2014, 116, 223-242. [CrossRef] [PubMed]

32. Peden, R.S.E.; Akaichi, F.; Camerlink, I.; Boyle, L.A.; Turner, S.P. Factors Influencing Farmer Willingness to Reduce Aggression between Pigs. Animals 2018, 9, 6. [CrossRef]

33. Bracke, M.B.M.; De Lauwere, C.C.; Wind, S.M.M.; Zonerland, J.J. Attitudes of Dutch Pig Farmers Towards Tail Biting and Tail Docking. J. Agric. Environ. Ethics 2013, 26, 847-868. [CrossRef]

34. Carroll, G.A.; Boyle, L.A.; Hanlon, A.; Collins, L.; Griffin, K.; Friel, M.; Armstrong, D.; O'Connell, N.E. What can carcass-based assessments tell us about the lifetime welfare status of pigs? Livest. Sci. 2018, 214, 98-105. [CrossRef]

35. Tan, S.S.L.; Shackleton, D.M.; Beames, R.M. The effect of mixing unfamiliar individuals on the growth and production of finishing pigs. Anim. Sci. 1991, 52, 201-206. [CrossRef]

36. Van Staaveren, N.; Teixeira, D.L.; Hanlon, A.; Boyle, L.A. Pig carcass tail lesions: The influence of record keeping through an advisory service and the relationship with farm performance parameters. Animal 2017, 11. [CrossRef] [PubMed]

37. EFSA. Scientific Opinion on the public health hazards to be covered by inspection of meat (swine). EFSA J. 2011, 9, 2351. [CrossRef]

38. vom Brocke, A.L.; Karnholz, C.; Madey-Rindermann, D.; Gauly, M.; Leeb, C.; Winckler, C.; Schrader, L.; Dippel, S. Tail lesions in fattening pigs: Relationships with postmortem meat inspection and influence of a tail biting management tool. Animal 2018, 1-10. [CrossRef] [PubMed]

39. Dawkins, M.S. Animal welfare and efficient farming: Is conflict inevitable? Anim. Prod. Sci. 2017, 57, $201-208$. [CrossRef]

40. Rault, J.-L.; Holyoake, T.; Coleman, G. Stockperson attitudes toward pig euthanasia. J. Anim. Sci. 2017, 95, 949-957. [CrossRef]

41. Morrow, W.E.M.; Meyer, R.E.; Roberts, J. Financial and welfare implications of immediately euthanizing compromised nursery pigs. J. Swine Heal. Prod. 2006, 14, 25-34.

42. Turner, P.V.; Doonan, G. Developing on-farm euthanasia plans. Can. Vet. J. = La Rev. Vet. Can. 2010, 51, 1031-1034.

43. Farm Animal Welfare Advisory Council (FAWAC). Animal Welfare Guidelines for Guidelines for Emergency Killing of Pigs on Farm; Department of Agricultur, Food and the Marine: Dublin, Ireland, 2017. 
44. Sanchez-Vazquez, M.J.; Nielen, M.; Edwards, S.A.; Gunn, G.J.; Lewis, F.I. Identifying associations between pig pathologies using a multi-dimensional machine learning methodology. BMC Vet. Res. 2012, 8, 151. [CrossRef] [PubMed]

45. Ritter, M.J.; Ellis, M.; Berry, N.L.; Curtis, S.E.; Anil, L.; Berg, E.; Benjamin, M.; Butler, D.; Dewey, C.; Driessen, B.; et al. Review: Transport Losses in Market Weight Pigs: I. A Review of Definitions, Incidence, and Economic Impact. Prof. Anim. Sci. 2009, 25, 404-414. [CrossRef]

46. Averos, X.; Knowles, T.G.; Brown, S.N.; Warriss, P.D.; Gosalvez, L.F. Factors affecting the mortality of pigs being transported to slaughter. Vet. Rec. 2008, 163, 386-390. [CrossRef] [PubMed]

47. Spoolder, H.A.M.; Bracke, M.B.M.; Mueller-Graf, C.; Edwards, S. Technical report submitted to EFSA. Preparatory work for the future development of animal based measures for assessing the welfare of pigs. Report 2: Preparatory work for the future development of animal based measures for assessing the welfare of weaned. EFSA Support. Publ. 2011, 8, 181E. [CrossRef]

48. Teixeira, D.L.; Harley, S.; Hanlon, A.; O'Connell, N.E.; More, S.J.; Manzanilla, E.G.; Boyle, L.A. Study on the Association between Tail Lesion Score, Cold Carcass Weight, and Viscera Condemnations in Slaughter Pigs. Front. Vet. Sci. 2016, 3, 24. [CrossRef] [PubMed]

49. Taylor, N.R.; Parker, R.M.A.; Mendl, M.; Edwards, S.A.; Main, D.C.J. Prevalence of risk factors for tail biting on commercial farms and intervention strategies. Vet. J. 2012, 194, 77-83. [CrossRef] [PubMed]

50. Chapinal, N.; Weary, D.M.; Collings, L.; von Keyserlingk, M.A.G. Lameness and hock injuries improve on farms participating in an assessment program. Vet. J. 2014, 202, 646-648. [CrossRef] [PubMed]

51. Lambton, S.L.; Nicol, C.J.; Friel, M.; Main, D.C.J.; McKinstry, J.L.; Sherwin, C.M.; Walton, J.; Weeks, C.A. A bespoke management package can reduce levels of injurious pecking in loose-housed laying hen flocks. Vet. Rec. 2013, 172, 423. [CrossRef] [PubMed]

52. Ambrosius, F.H.W.; Hofstede, G.J.; Bock, B.B.; Bokkers, E.A.M.; Beulens, A.J.M. Modelling farmer decision-making: The case of the Dutch pork sector. Br. Food J. 2015, 117, 2582-2597. [CrossRef]

53. Rojo-Gimeno, C.; Postma, M.; Dewulf, J.; Hogeveen, H.; Lauwers, L.; Wauters, E. Farm-economic analysis of reducing antimicrobial use whilst adopting improved management strategies on farrow-to-finish pig farms. Prev. Vet. Med. 2016, 129, 74-87. [CrossRef] [PubMed]

54. D’Eath, R.B.; Niemi, J.K.; Vosough Ahmadi, B.; Rutherford, K.M.D.; Ison, S.H.; Turner, S.P.; Anker, H.T.; Jensen, T.; Busch, M.E.; Jensen, K.K.; et al. Why are most EU pigs tail docked? Economic and ethical analysis of four pig housing and management scenarios in the light of EU legislation and animal welfare outcomes. Animal 2016, 10, 687-699. [CrossRef] [PubMed]

55. Vom Brocke, A.L.; Madey, D.P.; Gauly, M.; Schrader, L.; Dippel, S. Training veterinarians and agricultural advisers on a novel tool for tail biting prevention. Vet. Rec. Open 2015, 2, e000083. [CrossRef] [PubMed]

56. Teagasc. The National Pig Herd Performance Report-2015; Teagasc, Pig Development Department, Moorepark: Fermoy, Ireland, 2016.

57. Larsen, A.B.L.; Hviid, M.S.; Jorgensen, M.E.; Larsen, R.; Dahl, A.L. Vision-based method for tracking meat cuts in slaughterhouses. Meat Sci. 2014, 96, 366-372. [CrossRef] [PubMed]

58. Brandt, P.; Aaslyng, M.D. Welfare measurements of finishing pigs on the day of slaughter: A review. Meat Sci. 2015, 103, 13-23. [CrossRef] [PubMed]

59. Aaslyng, M.D.; Larsen, H.D.; Nielsen, G.B.; Black, P. Measuring tail length and tail bites on pig carcasses. In Proceedings of the 7th International Conference on the Assessment of Animal Welfare at Farm and Group Level; De Jong, I.C., Koene, P., Eds.; Wageningen Academic Publishers: Wageningen, The Netherlands, 2017; p. 263.

60. Blömke, L.; Fels, M.; Kemper, N. Automated rating of welfare indicators for pigs in the slaughterhouse-A pilot study. In Proceedings of the 24th International Pig Veterinary Society Congress \& 8th European Symposium of Porcine Health Management, Dublin, Ireland, 7-10 June 2016; p. 633.

61. Amaral, T.; Plötz, T.; McKenna, S.; Carter, T.; Yuill, K.; Waters, J.; Kyriazakis, I. Image analysis for automated detection of abnormal organs in pig offal. In Proceedings of the 24th International Pig Veterinary Society Congress \& 8th European Symposium of Porcine Health Management, Dublin, Ireland, 7-10 June 2016; p. 123. 
62. Brandt, P.; Aaslyng, M.D.; Rousing, T.; Schild, S.L.A.; Herskin, M.S. The relationship between selected physiological post-mortem measures and an overall pig welfare assessment from farm to slaughter. Livest. Sci. 2015, 180, 194-202. [CrossRef]

63. Doyle, B.; Hanlon, A.; O'Connell, N.; Boyle, L. The Development of Ante Mortem and Post Mortem Meat Inspection as a Diagnostic Tool for Pig Health and Welfare; Teagasc, Pig Development Department, Moorepark: Fermoy, Ireland, 2016.

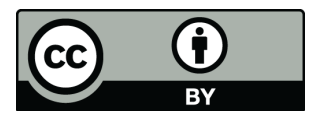

(C) 2019 by the authors. Licensee MDPI, Basel, Switzerland. This article is an open access article distributed under the terms and conditions of the Creative Commons Attribution (CC BY) license (http:/ / creativecommons.org/licenses/by/4.0/). 